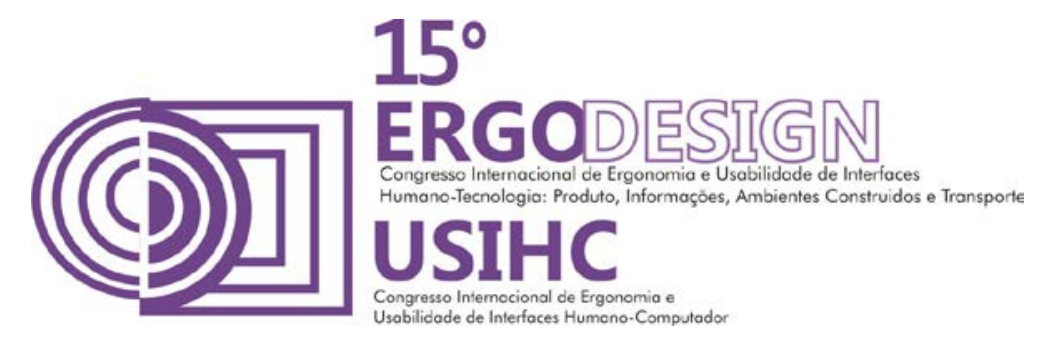

\title{
ANÁLISE DA ATIVIDADE TROCA DE ÓLEO AUTOMOTIVO EM OFICINA MECÂNICA E SUAS SOBRECARGAS MUSCULO-ESQUELÉTICAS
}

\author{
NECHO, Thaís dos Santos (1); \\ LATTA, Poliane Cardoso de Souza (2); \\ SANTOS, Maria Isabel (3); \\ RODRIGUES, Michele (4); \\ STAMATO, Cláudia (5) \\ (1) PUC-Rio, Especialização em Ergonomia \\ e-mail: thaisnecho@gmail.com.br \\ (2) PUC-Rio, Especialização em Ergonomia \\ e-mail: poliane.csl@gmail.com \\ (3) PUC-Rio, Especialização em Ergonomia \\ e-mail: mariaisabel2610@hotmail.com \\ (4) PUC-Rio, Especialização em Ergonomia \\ e-mail: ergomrg@gmail.com \\ (5) PUC-Rio, Doutorado em Design \\ e-mail: stamatoclaudia@gmail.com
}

\begin{abstract}
RESUMO
Este texto apresenta uma avaliação da atividade mais frequentemente realizada em uma oficina mecânica, a troca de óleo de veículo automotivo no nível do solo. Os resultados obtidos nas etapas de Diagnose e Projetação Ergonômicas do método Intervenção Ergonomizadora (MORAES \& MONT'ALVÃO, 2010), serão aqui expostos. Foram contemplados os registros posturais dos métodos RULA, OWAS e REBA assim como o Diagrama de Corlett e o questionário Nórdico. Percebeu-se a existência real de riscos biomecânicos para a coluna cervical, coluna lombar e região dos ombros na atividade laboral destes trabalhadores.
\end{abstract}




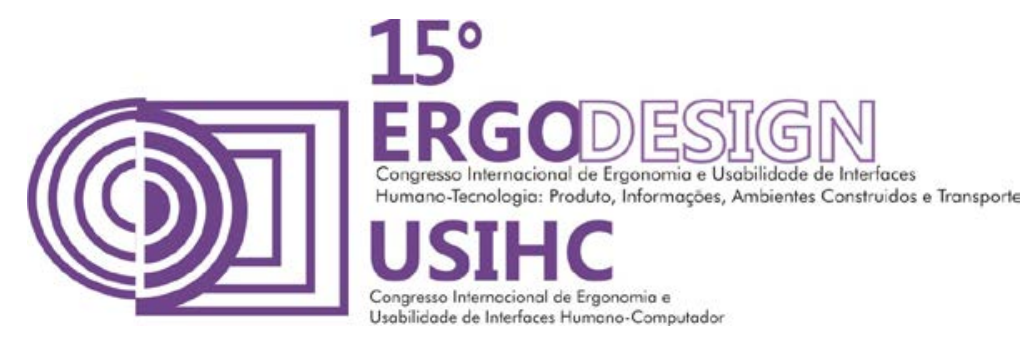

\begin{abstract}
This text presents an evaluation of the activity more frequently carried out in a garage, theexchange of oil of vehicle in the level of the ground. The results obtainedin the stages of Diagnosis and Projection Ergonomics of the method Ergonomic Intervention (MORAES \& MONT'ALVÃO,2010), will be here exposed. The registers were comtemplated posturals of the methods RULA, OWAS and REBA as well as the Diagram of Corlett and the Nordic Questionnaire. The real risks existence was realized biomecanics for the cervical column, lumbar column and region of shoulders in the activity laboral of these workes.
\end{abstract}

\title{
1. INTRODUÇÃO
}

O presente estudo tem como objetivo principal a identificação dos riscos posturais e biomecânicos relacionados ao esforço físico da atividade de troca de óleo automotivo no nível do solo em uma oficina mecânica. A partir de uma avaliação baseada nos resultados obtidos em análises de diferentes métodos posturais como registros de posturas, OWAS, RULA, REBA e o Diagrama/ Questionário de Corlett buscou-se a retificação das posturas para adequada realização da tarefa.

A oficina mecânica ambiente deste estudo é parte de uma empresa de terceirização de serviços, e seu expediente é de segunda a sexta-feira das 8 horas às 18 horas com uma hora para almoço e sem pausas programadas para descanso durante a jornada de trabalho. A equipe é formada por três funcionários, sendo dois mecânicos com experiência de aproximadamente 20 anos e um ajudante que recebe treinamento diário. Todos trabalham na análise e manutenção de uma frota com 80 veículos que são utilizados diariamente.

O levantamento anual dos Relatórios Operacionais baseado nos registros de julho de 2013 a junho de 2014 apontou que a oficina mecânica oferece 135 serviços distintos e que destes serviços, o reparo mais executado foi a troca de óleo automotivo com 110 entradas, seguido pela troca da pastilha de freio com 18 entradas e trocas de bateria e pneus com 17 e 15 entradas respectivamente. Consta no mesmo relatório 24 entradas de serviço não identificado.

\section{$1.1 \quad$ A Troca de Óleo}

A oficina mecânica em questão atende exclusivamente aos veículos de trabalho da empresa, utilizados por funcionários próprios para atender aos setores internos e contratos externos. Os veículos foram adquiridos há seis anos e são usados diariamente, fazendo-se necessária a realização de manutenção preventiva duas vezes ao ano. Entre as atividades já mencionadas anteriormente, a troca de óleo, foi apontada pelos registros da empresa, como a atividade mais frequente desta oficina mecânica, com uma proporção $26,25 \%$ em relação ao total de atividades. O padrão da empresa exige que as trocas de óleo devem ser agendadas previamente e acontecer assim que o automóvel atinja $5.000 \mathrm{~km}$.

Para execução deste serviço, de duração aproximada de 15 minutos, é necessário apenas um mecânico que segue alguns passos pré-determinados: Após estacionar o veículo, o mecânico o eleva com o auxílio de um macaco hidráulico e dispõe um papelão no chão como uma proteção para ele se deitar no nível do solo a fim de posicionar, debaixo do veículo, o galão coletor de 


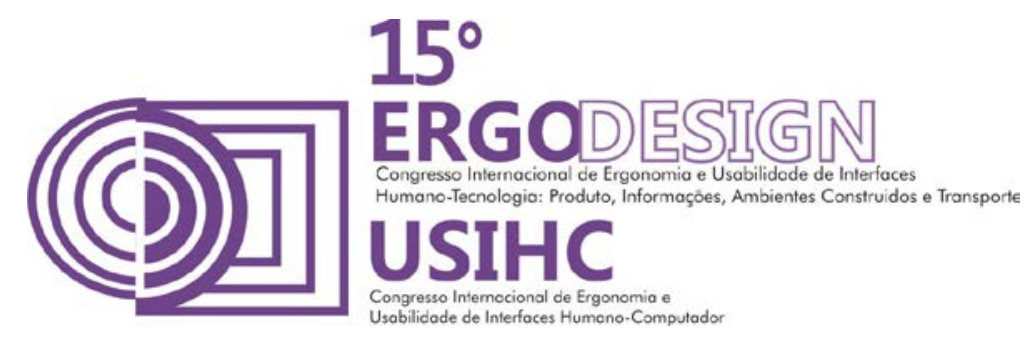

óleo usado. Deitado retira o tampão do cárter para iniciar o processo de coleta do óleo usado. Com o reservatório de óleo esvaziado, o usuário recoloca o tampão do cárter e retira o galão coletor de baixo do veículo. Abaixa o veículo e guarda o macaco hidráulico, pega um galão com óleo novo e com a ajuda de um funil despeja na entrada do reservatório de óleo. O processo termina com a aferição do nível do óleo através da paleta do óleo e o registro da quilometragem atual do veículo em um adesivo colado no vidro para-brisa.

Apesar dos documentos apresentados pela empresa, verificou-se que nem todos os serviços, incluindo as trocas de óleo, eram registrados devidamente o que pressupõe uma frequência ainda maior que aquela apresentada. Segundo os profissionais da oficina a sua execução é simples e rápida e em muitos momentos os responsáveis pelos veículos necessitam destes prontamente para continuidade do dia de trabalho. Isso significa que a troca de óleo deve ser realizada assim que o veículo adentra a oficina e este imediatismo pode ser uma explicação para os registros em menor número que a realidade. Devido a estes fatores circunstanciais a maioria dos mecânicos opta por fazer a troca do óleo de forma mais rápida o que implica na adoção de posturas prejudiciais ao sistema esquelético, atingindo principalmente a coluna vertebral.

\subsection{Diagnose ergonômica}

"A diagnose ergonômica permite aprofundar os problemas priorizados e testar predições. (...) $E$ o momento das observações sistemáticas das atividades da tarefa, dos registros de comportamento, em situação real de trabalho" (MORAES \& MONT'ALVÃO, 2010, 80).

Nesta etapa foram identificados problemas em diferentes subsistemas, a seguir estão relacionados os problemas específicos do subsistema interfacial, que está diretamente ligado às sobrecargas musculoesqueléticas.

De acordo com a ascensão postural, observou-se que durante a troca de óleo no nível do solo, o usuário adota posturas prejudiciais para conseguir visualizar e alcançar as peças do veículo, fazendo movimentos repetitivos com a cabeça, coluna cervical e várias flexões de tronco para alcançar peças e ferramentas que ele apoia no chão.

Ao final de um dia de expediente normal, um pesquisador aplicou o Questionário Nórdico e o Diagrama de Corlett (Figura 1) em sequência para os três empregados presentes, individualmente.

\subsection{Diagrama de Corlett e Questionário Nórdico}

O diagrama de Corlett foi proposto por Corlett e Manenica (1980), para facilitar a localização de áreas dolorosas utilizando um desenho do corpo humano dividido em 24 segmentos (IIDA, 2005). Esse diagrama é de fácil entendimento e pode ser aplicado para grandes grupos, mas como a oficina mecânica conta apenas com 3 empregados, optamos por um entrevistador aplica-lo individualmente.

Neste teste, o usuário foi solicitado a marcar a região do diagrama do corpo humano onde costuma sentir dor/desconforto. Tomando como base a escala progressiva de dor/desconforto mostrada na figura 1 , o empregado assinalou na figura o número que achou correspondente a 


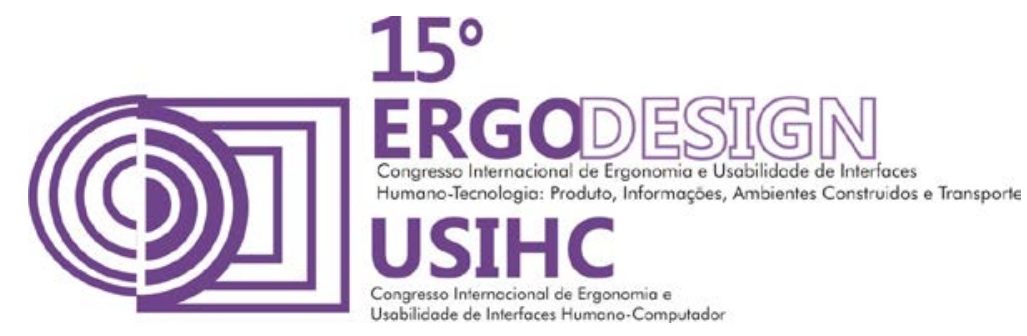

intensidade desta dor/desconforto. Na figura 1, representamos a intensidade do desconforto/dor pelas cores.

O Questionário Nórdico foi desenvolvido de maneira a facilitar o seu autopreenchimento, onde o trabalhador deve responder com "sim" ou "não" a três perguntas em relação às partes do corpo que ele relatar algum tipo de dor/desconforto (IIDA, 2005):

- Você teve algum problema nos últimos 7 dias?

- Você teve algum problema nos últimos 12 meses?

- Você teve que deixar de trabalhar algum dia nos últimos 12 meses?

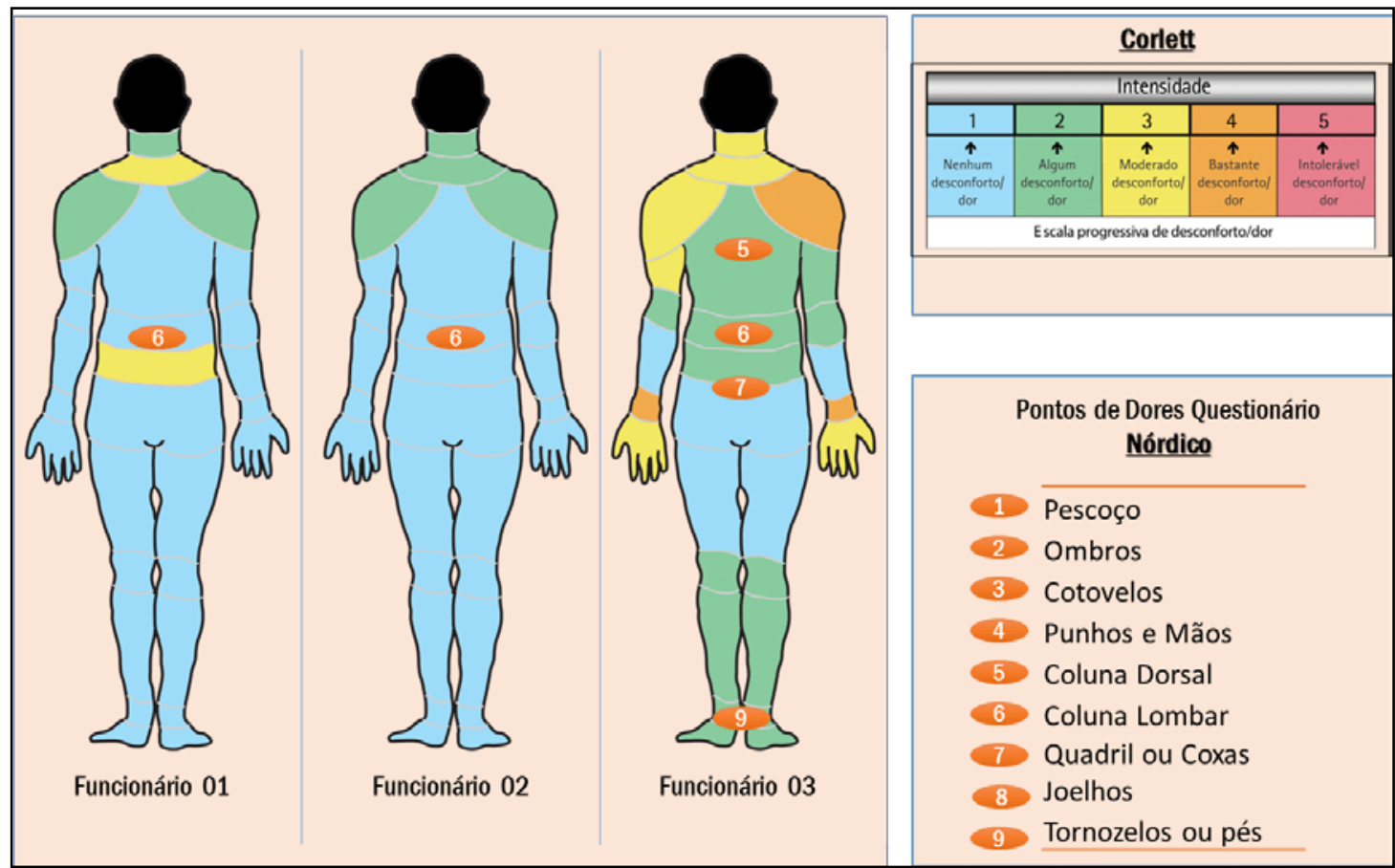

Figura 1- Resultado do Diagrama de Corlett e Questionário Nórdico aplicado.

Resultado do Diagrama de Corlett: O Funcionário 1 relatou algum desconforto/dor nos ombros e na região do pescoço relatou duas intensidades diferentes sendo moderado desconforto/dor mais próximo a cabeça e algum desconforto/dor na região cervical. O Funcionário 2 apresentou algum desconforto/dor no pescoço e ombros. O Funcionário 3 apontou algum desconforto/dor em dorso superior, médio e inferior, braço direito, pernas e pés; moderado desconforto/dor no pescoço, ombro esquerdo, braço esquerdo e mãos; bastante desconforto/dor no ombro direito e ante braço.

Resultado do Questionário Nórdico: Os Funcionários 1 e 2 relataram ter tido algum problema na coluna lombar nos últimos 12 meses, mas sem afastamento do trabalho. O funcionário 3 apontou ter tido algum problema na coluna dorsal, coluna lombar, no quadril e tornozelos/pé 


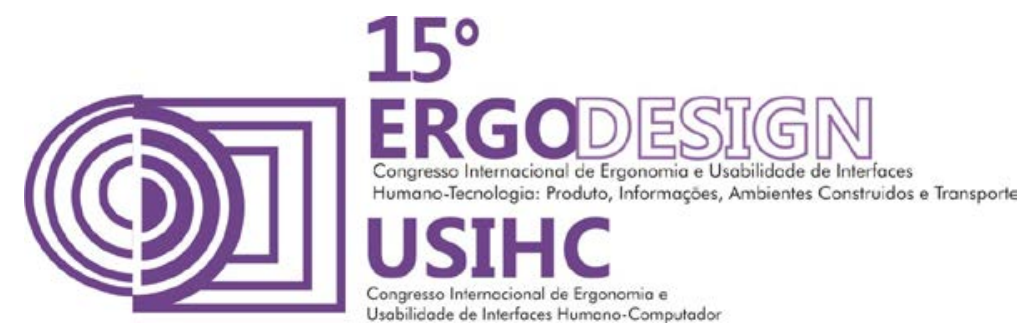

nos últimos 7 dias e que estas dores persistem a mais de 12 meses, mas nunca teve que deixar de trabalhar.

Analisando os resultados obtidos nos dois questionários, observamos diferença de respostas do mesmo funcionário. Como utilizamos os dois questionários com o objetivo de ser uma análise complementar, os resultados nos possiblitou mapear as regiões do corpo que mais sentem a pressão da rotina de trabalho numa oficina mecânica.

Depois destas avaliações fizemos um Registro Comportamental da troca de óleo (Tabela 1), analisando os movimentos da cabeça/coluna cervical, ombros, braços/cotovelos, punhos e tronco a cada dois segundos. Ficou comprovado que os movimentos de cabeça/coluna cervical e tronco mais executados são os que causam maior sobrecarga na coluna, o que justifica as reclamações de dor/desconforto dos funcionários ao final da jornada de trabalho. Na tabela 1 observamos que o funcionário fica $40 \%$ do tempo de realização da tarefa com a cabeça flexionada, 34\% do tempo com o tronco em inclinação lateral, 33\% do tempo fazendo o movimento de rotação associada a inclinação lateral de tronco e $14 \%$ do tempo em flexão de tronco. Os registros de movimentos do ombro mostram que $72 \%$ do tempo o funcionário adota uma posição neutra do mesmo, e os movimentos do punho acontecem dentro do ângulo de conforto de movimentação, o que impossibilita associar as reclamações dos funcionários à troca de óleo.

Tabela 1. Resultado do Registro Comportamental

\begin{tabular}{|c|c|c|c|}
\hline \multicolumn{2}{|c|}{ CABEÇA/COLUNA CERVICAL } & \multicolumn{2}{|l|}{ PUNHO } \\
\hline Flexão & $40 \%$ & Neutro & $30 \%$ \\
\hline Rotação à Direita & $33 \%$ & Extensão & $28 \%$ \\
\hline Inclinação & $22 \%$ & Flexão & $16 \%$ \\
\hline Neutro & $5 \%$ & Extensão com resistência & $14 \%$ \\
\hline \multicolumn{2}{|c|}{ OMBRO } & Fora & $12 \%$ \\
\hline Neutro & $72 \%$ & & \\
\hline Abdução & $19 \%$ & \multicolumn{2}{|l|}{ TRONCO } \\
\hline Fexão & $6 \%$ & Inclinação Lateral & $34 \%$ \\
\hline Extensão & $3 \%$ & Rotação + Inclinação Lateral & $33 \%$ \\
\hline \multicolumn{2}{|c|}{ BRAÇO/COTOVELO } & Neutro & $19 \%$ \\
\hline Neutro & $32 \%$ & Flexão & $14 \%$ \\
\hline Flexão & $29 \%$ & & \\
\hline Pronado com flexão & $23 \%$ & & \\
\hline Extensão & $16 \%$ & & \\
\hline
\end{tabular}

Depois de avaliar as respostas apontadas no questionários e as posturas mais executadas no registro comportamental, chegamos às três posturas mais complexas desta tarefa:

A- Retirada do óleo usado do carro: usuário deitado no chão, em decúbito dorsal, realizando flexão e rotação de tronco para conseguir alcançar o tampão do cárter e o galão de descarte do óleo usado; 

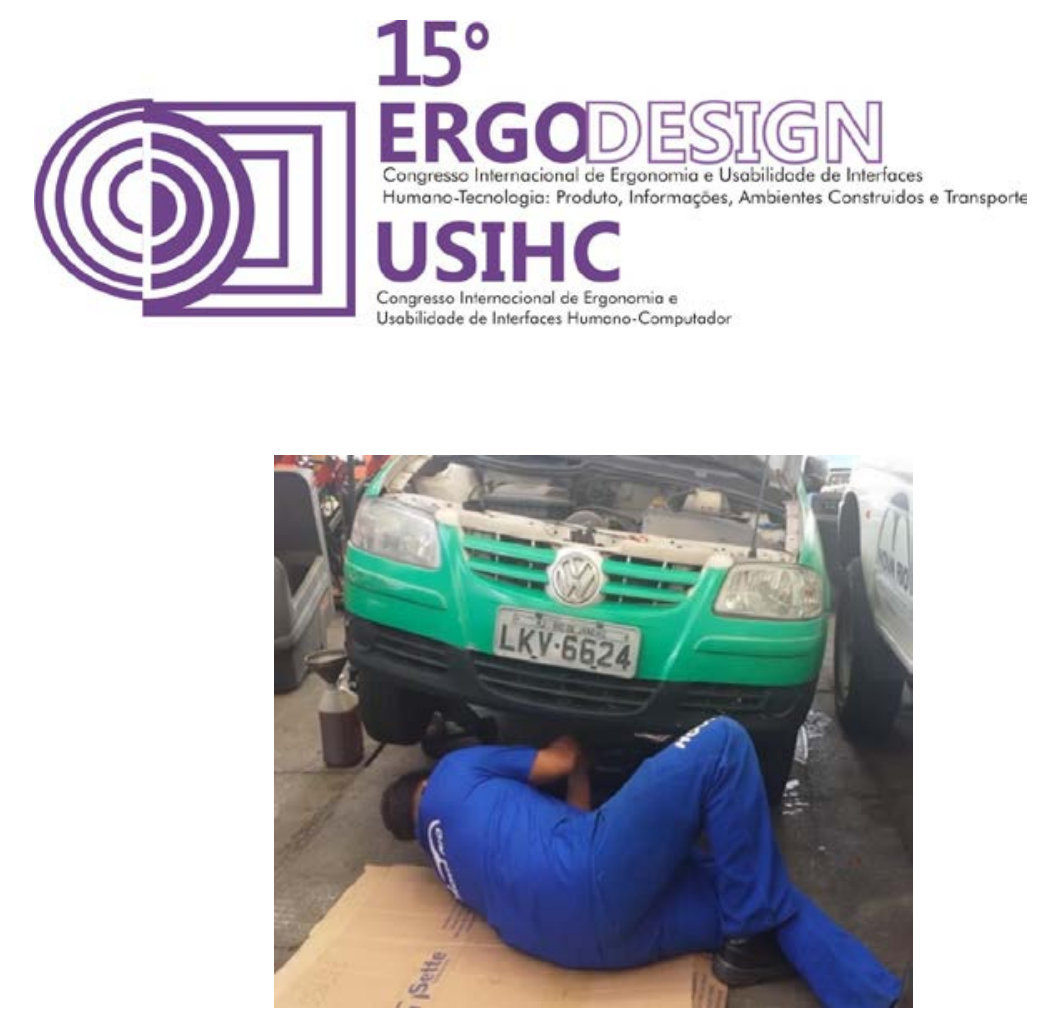

Figura 2, Funcionário deitado sob o carro para retirada do óleo usado.

B- Apoio e retirada do galão de óleo novo no chão: usuário realizando rotação de tronco associada a inclinação lateral acentuada apoiando-se em apenas uma das pernas (Figura 2);

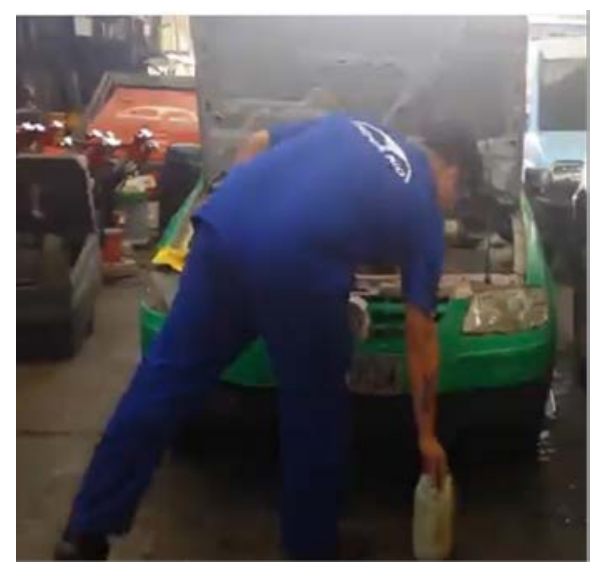

Figura 3, Funcionário apoiando o galão de óleo novo no chão.

C- Alimentação do reservatório do veículo com óleo novo: usuário em pé posicionado de frente para o motor do carro segurando o galão de óleo novo e realizando leve inclinação lateral de tronco e flexão da cabeça/coluna cervical. 

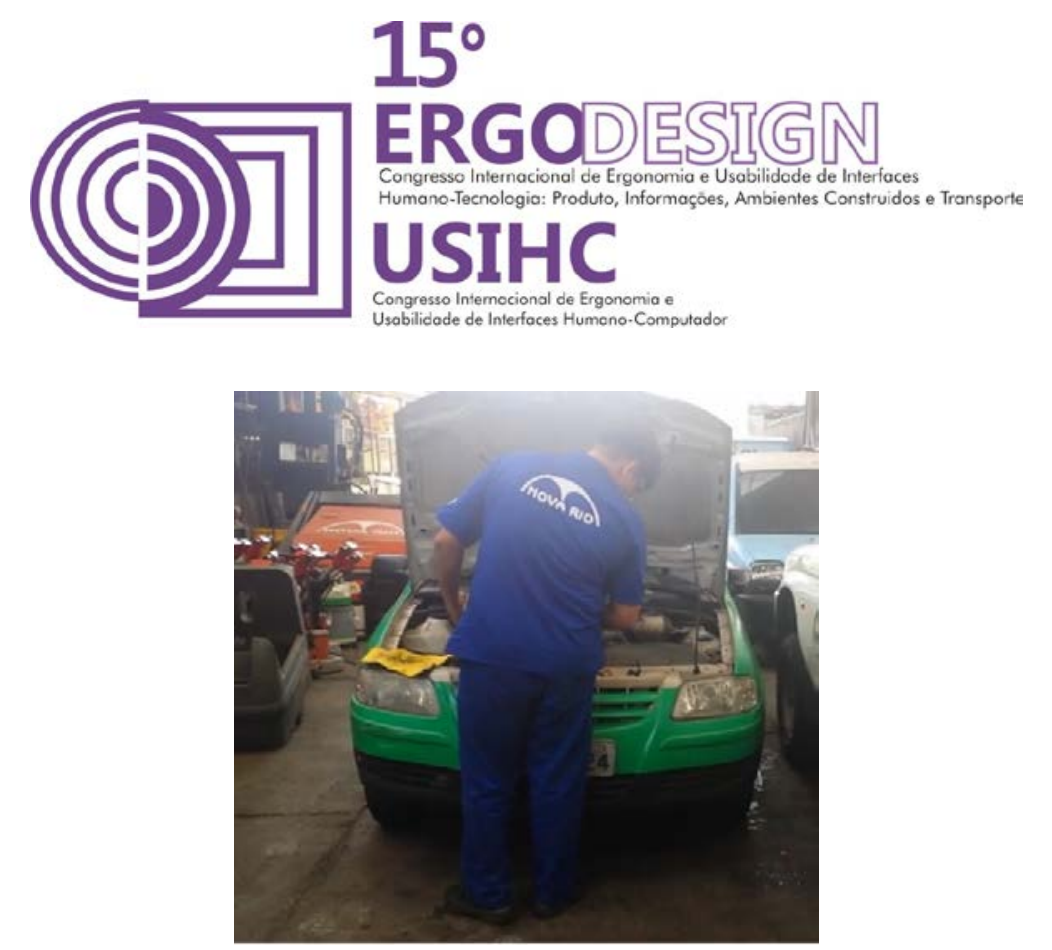

Figura 4, Alimentação do reservatório do veículo com óleo novo.

\subsection{Método RULA}

Criado para avaliar a exposição dos usuários aos fatores de risco que podem ocasionar constrangimentos em membros superiores do corpo, Lynn McAtamney e Nigel Corlett da Universidade de Nottingham criaram o Método RULA em 1993 (JUNIOR, 2009). Para sua aplicação, todos os fatores avaliados recebem uma pontuação e em seguida são inseridos em uma tabela, que nos fornecerá um valor que corresponde a um nível de ação e sua respectiva intervenção.

- Nível de ação 1 - Valores entre 1 e 2 - Postura aceitável, se não mantida ou repetida por longos períodos;

- Nível de ação 2 - Valores entre 3 e 4 - Indicam a necessidade de investigação mais detalhada e mudanças podem ser necessárias;

- Nível de ação 3 - Valores entre 5 e 6 - Indicam que a investigação e mudanças devem ocorrer brevemente;

- Nível de ação 4 - Valor 7 - Indica que investigação e mudanças são requeridas imediatamente.

A avaliação das condições do usuário na realização da troca de óleo obteve os seguintes resultados:

Tabela 2. Nível de ação, em função da pontuação final obtida - Método RULA.

\begin{tabular}{|c|c|c|}
\hline POSTURA & $\begin{array}{c}\text { NÍVEL DE } \\
\text { AÇÃO }\end{array}$ & INTERVENÇÃo \\
\hline A & 4 & Devem ser introduzidas mudanças imediatamente. \\
\hline
\end{tabular}




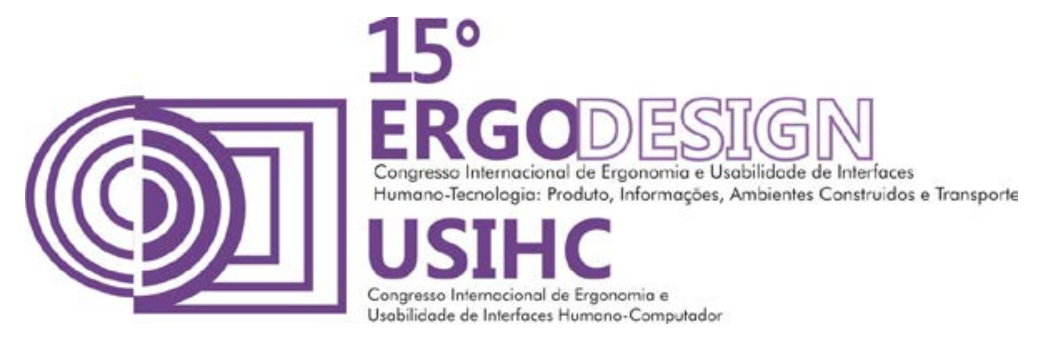

\begin{tabular}{|l|l|l|}
\hline B & 4 & Devem ser introduzidas mudanças imediatamente. \\
\hline C & 2 & $\begin{array}{l}\text { Deve-se realizar uma observação. } \\
\text { Podem ser necessárias mudanças. }\end{array}$ \\
\hline
\end{tabular}

Observa-se a necessidade de mudanças deste posto de trabalho, especialmente na atividade realizada no nível do piso e na fase de apoio do galão de óleo novo no chão.

\subsection{Método OWAS}

Criado na Finlândia pela OVAKI OY junto com o Instituto Finlandês de Saúde Ocupacional, o Método OWAS (Ovaco Working Analisys System) tem como objetivo examinar as posturas combinadas das costas, braços, pernas e forças aplicadas pelo trabalhador na execução da tarefa. Através da análise dessas posturas, é definida uma categoria de ação e sua respectiva intervenção (MÁSCULO \& VIDAL, 2011). O OWAS é uma ferramenta ergonômica muito útil na detecção de posturas inadequadas, pois sua aplicação aponta possíveis posturas que podem levar o usuário ao afastamento do trabalho devido à lesões por esforços excessivos. As categorias de ação são divididas em função da predominância de posturas adotadas para a execução de tarefas:

- Classe 1: postura normal, que dispensa cuidados, a não ser em casos excepcionais;

- Classe 2: postura que deve ser verificada na próxima revisão rotineira dos métodos de trabalho;

- Classe 3: postura que deve merecer atenção a curto prazo;

- Classe 4: postura que deve merecer atenção imediata.

Uma desvantagem do método OWAS é que ele não avalia a região cervical, punhos e antebraços e não é possível aplicá-la quando o trabalho é realizado na postura deitada.

Tabela 3. Nível de ação, em função da pontuação final obtida - Método OWAS.

\begin{tabular}{|c|c|l|}
\hline POSTURA & $\begin{array}{c}\text { CATEGORIA } \\
\text { DE AÇÃO }\end{array}$ & \multicolumn{1}{|c|}{ INTERVENÇÃo } \\
\hline A & - & Não foi possível avaliar \\
\hline B & 4 & Postura que deve merecer atenção imediata. \\
\hline C & 2 & $\begin{array}{l}\text { Postura que deve ser verificada na próxima revisão rotineira dos } \\
\text { métodos de trabalho. }\end{array}$ \\
\hline
\end{tabular}




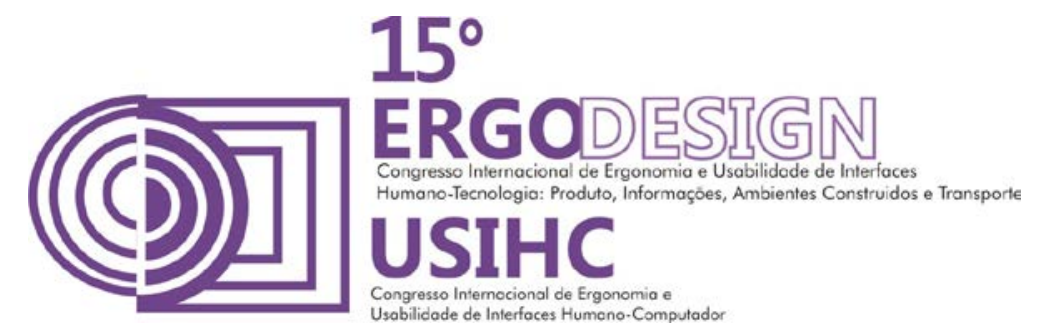

Observa-se a necessidade de mudanças no posto de trabalho deste usuário. A coleta do óleo usado do carro, executada com o usuário deitado no nível do piso, não pode ser avaliada, entretanto, quando o mesmo usuário deposita e retira o galão de óleo do chão, se enquadra no nível mais alto da categoria de ação, exigindo mudança imediata.

\subsection{Método REBA}

O método REBA (Rapid Intire Body Assessment) desenvolvido por Sue Hignett e Lynn McAtmney foi baseado nos métodos RULA, OWAS e NIOSH. Tem como objetivo avaliar posturas, forças aplicadas, tipos de movimentos, atividade muscular, trabalho repetitivo e o tipo de pega adotada pelo trabalhador ao realizar seu trabalho (HIGNETT \& MCATAMNEY, 2000). De acordo com a pontuação alcançada, é dado o nível do risco e a necessidade de intervenção:

- Pontuação 1 - Risco insignificante - Intervenção não é necessária;

- Pontuação 2 ou 3 - Risco baixo - Intervenção pode ser necessária;

- Pontuação 4 a 7- Risco médio - Intervenção necessária;

- Pontuação 8 a 10 - Risco alto - Intervenção necessária o quanto antes;

- Pontuação 11 ou mais - Risco muito alto - Intervenção necessária imediatamente.

A avaliação da condição do usuário realizando a troca de óleo obteve os seguintes resultados:

Tabela 4. Nível de ação, em função da pontuação final obtida - Método REBA.

\begin{tabular}{|c|c|l|}
\hline POSTURA & PONTUAÇÃO & RESULTADOI INTERVENÇÃo \\
\hline A & 5 & Risco alto/ Necessária o quanto antes. \\
\hline B & 8 & Risco alto/ Necessária o quanto antes. \\
\hline C & 9 & Risco médio / Necessária \\
\hline
\end{tabular}

Observa-se a necessidade de mudanças nesse posto de trabalho, especialmente em relação a postura deitada no nível do piso e na fase de apoio do galão de óleo novo no chão.

\section{CONCLUSÃO}

A parte acima da cintura de um adulto pesa em média $40 \mathrm{~kg}$ (DUL, 2012), o que faz com que nos movimentos de flexão de tronco aconteça uma contração dos músculos das costas para conseguir segurar o movimento, o que pode originar dores e desconforto na região da coluna lombar como os relatados pelos funcionários. O movimento de rotação, torção, do tronco é 


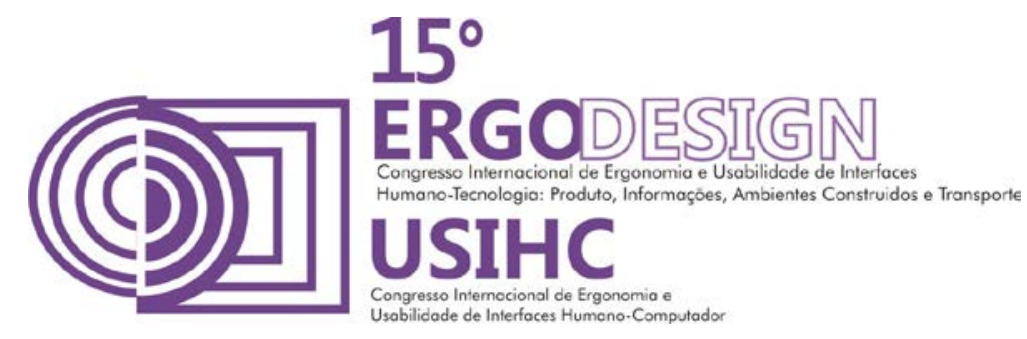

igualmente perigoso, pois causam tensões indesejáveis nas vértebras, tensionando os discos intervertebrais e gerando tensões desiguais nos dois lados da coluna vertebral.

Especialistas indicam a postura deitada apenas para repouso, por não haver tensão em nenhuma parte do corpo. Mas no caso de ter que realizar uma tarefa, como visualizar e/ou alcançar uma peça embaixo do carro, essa posição pode se tornar fatigante, pois a cabeça pesa em média de 4 a 5 kg (IIDA, 2005) e sustenta-la por alguns minutos já é suficiente para que o funcionário sinta dor na região do pescoço.

Com a análise desses pontos levantados na Diagnose Ergonômica, foi verificada a necessidade de projetar uma vaga exclusiva para troca de óleo, delimitando um espaço onde caiba um elevador automotivo com rampa de acesso e que eleve o carro a altura máxima de 1,98m e um carrinho de apoio, onde todos os itens necessários para a execução da tarefa (galão de óleo novo, galão receptor do óleo usado e ferramentas para abertura do tampão do cárter) encontrem-se dentro da área acional confortável do usuário.

O Projeto eleva o automóvel ao nível de acionamento dos usuários de maneira a otimizar o trabalho e evitar a exposição às sobrecargas na coluna cervical, toráxica e lombar. A manipulação de variados níveis de altura do veículo evita que os usuários flexionem o pescoço além dos ângulos de conforto para visualizar o motor (Figura 7) e reduz a tensão na coluna cervical, quadril e cintura escapular, pois substitui a postura deitada pela postura ereta e permite acionamentos sem mais contrangimentos (Figura 6).

Em todos os métodos utilizados no desenvolvimento deste estudo foi observada a necessidade imediata de reavaliação do momento em que o usuário apoia e aciona o galão de óleo novo no nível do piso. O esforço realizado para o levantamento e sustentação do galão determinou a necessidade de um carrinho com ajustes de altura e com espaços separados para apoio do galão receptor de óleo usado, galão de óleo novo e ferramentas necessárias para retirar o tampão do cárter, o que reduziu significativamente a sobrecarga musculoesqueletica das estruturas apontadas (Figura 5). 

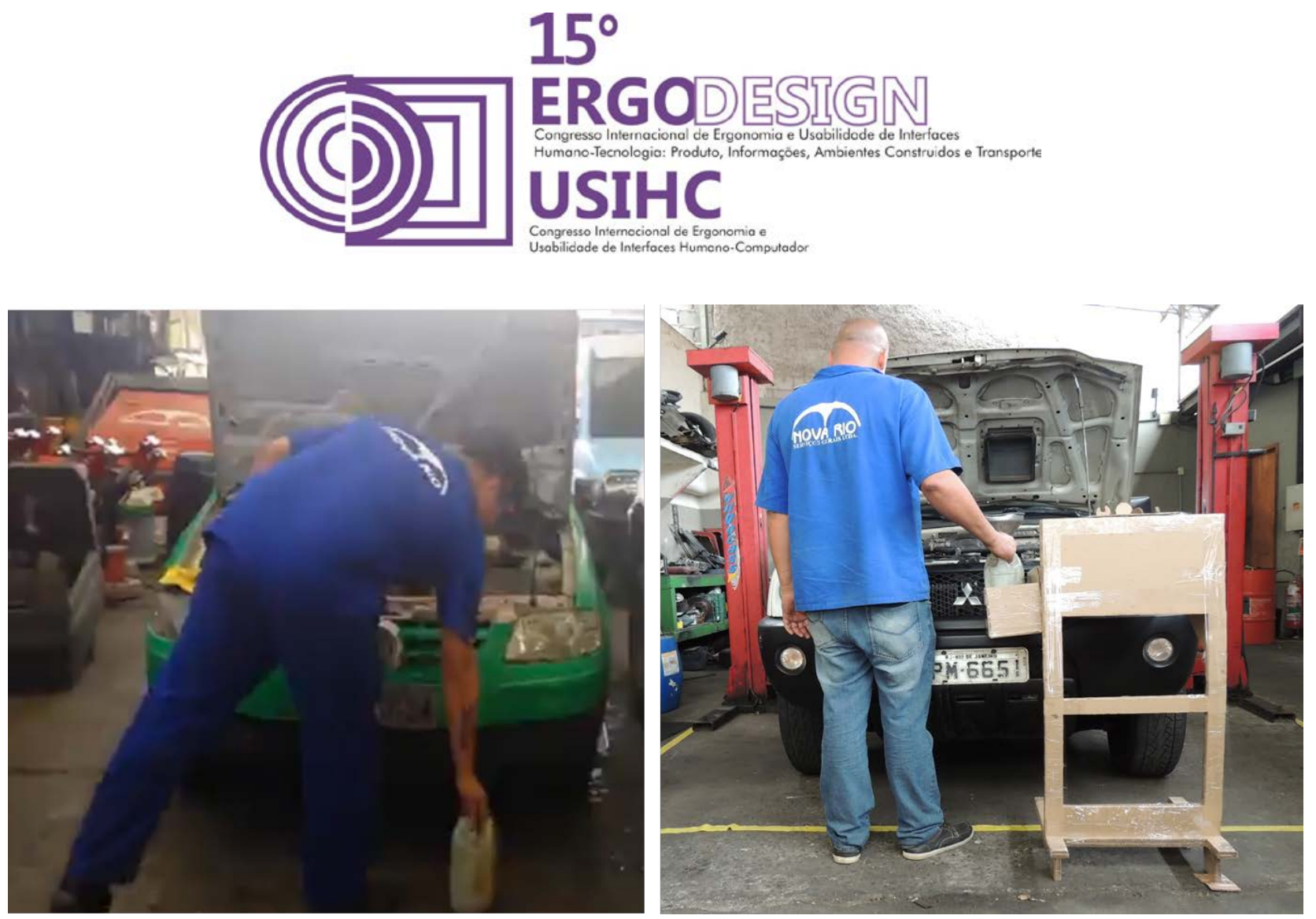

Figura 5- Momento de apoio e retirada do galão de óleo novo, antes no chão e depois do projeto apoiando no carrinho.
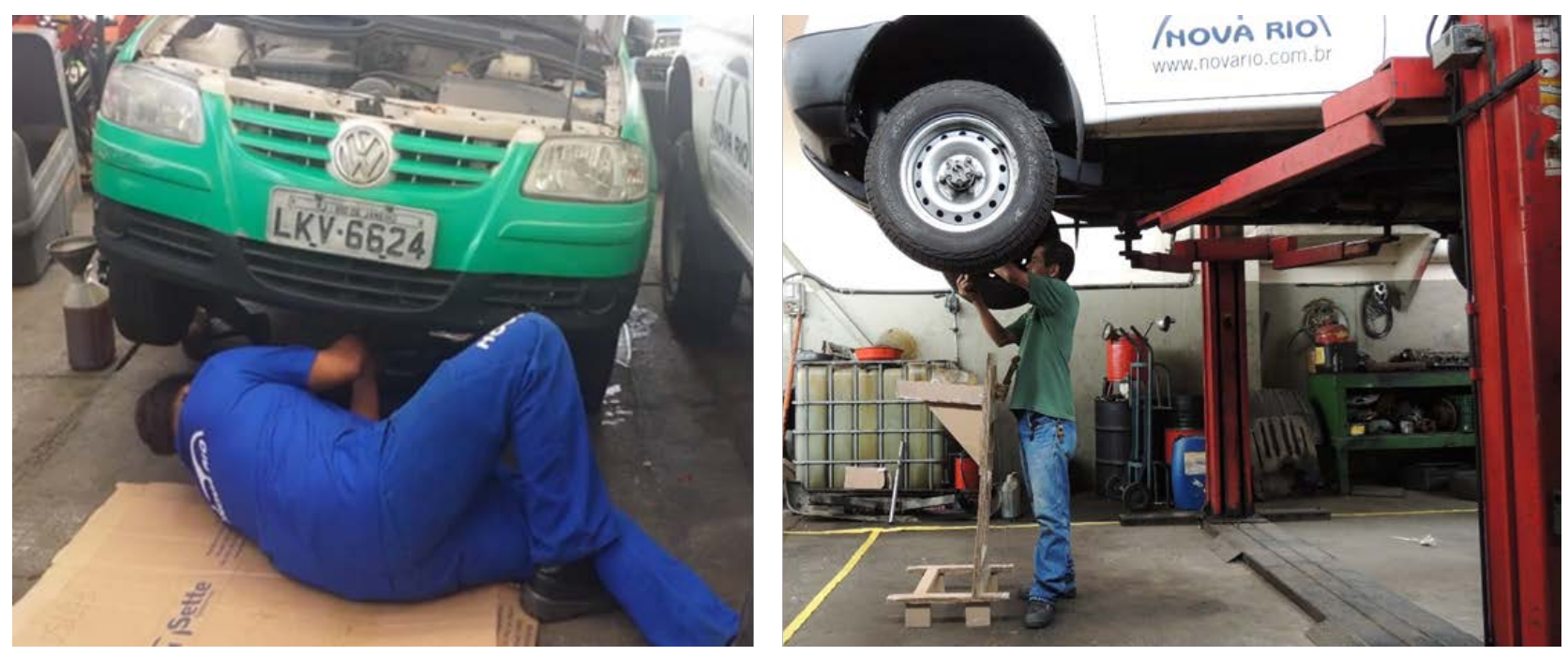

Figura 6- Momento de abertura do tampão do cárter e retirada do óleo do carro, antes no chão e depois do projeto com o carro suspenso no elevador automotivo. 

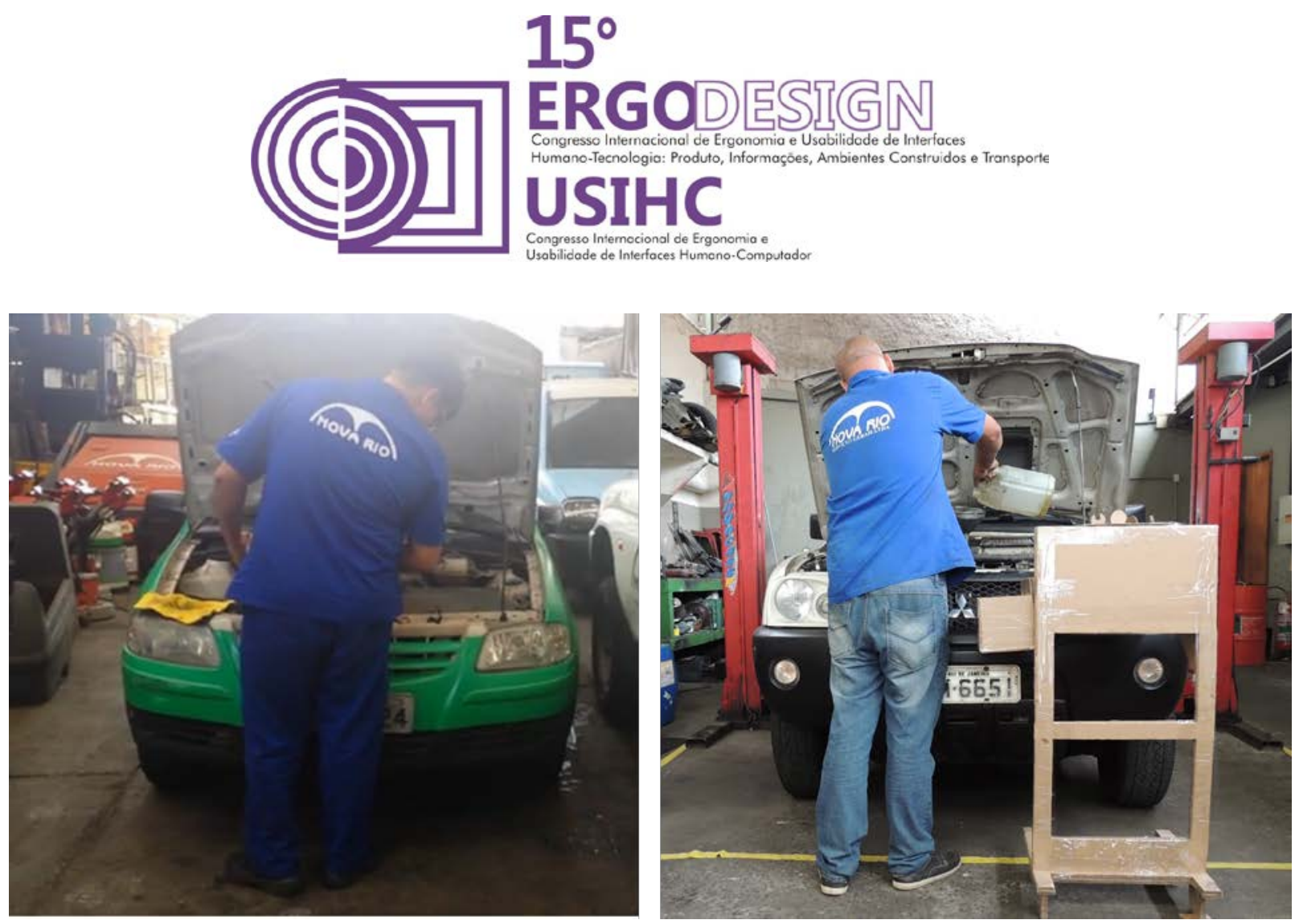

Figura 7- Antes e depois do momento de colocação do óleo novo no motor do carro.

\section{REFERÊNCIAS BIBLIOGRÁFICAS}

IIDA, I. Ergonomia: projeto e produção - 21 a edição rev. e ampl. São Paulo: Edgard Blücher, 2005.

MORAES, A. e MONT'ALVÃO, C. Ergonomia: Conceitos e Aplicações. Rio de Janeiro: 2AB. 4ª Edição Ver. Ampliada. Teresópolis, 2010.

DULL, Jan; WEERDMEESTER, Bernard. Ergonomia Prática. Trad. Itiro lida. $3^{\circ}$ Edição. São Paulo: Blucher, 2012

HIGNETT, S., MCATAMNEY, L. Rapid entire body assessment (REBA), "Applied Ergonomics". 2000: 31, 201-205.

JUNIOR, J. Diretrizes para uso das ferramentas de avaliação de carga física de trabalho em ergonomia: Equação NIOSH e Protocolo RULA. 2009. 146 f. Dissertação (Mestrado em Engenharia de Produção) Universidade Federal de Santa Catarina. Florianópolis. 2009.

MÁSCULO, F. S.; VIDAL, M. C. Ergonomia: Trabalho adequado e eficiente. Rio de Janeiro: Elsevier Ltda,2011. 